\title{
Remoção de células somáticas pela microfiltração não afeta a composição e a proteólise do leite
}

\author{
Somatic cell removal by microfiltration does not affect composition and proteolysis of milk
}

\author{
Marcos Veiga dos Santos ${ }^{1}$ Carlos Augusto Fernandes Oliveira ${ }^{2}$ \\ Ygor Vinícius Real de Lima ${ }^{1}$ \\ Bruno Garcia Botaro ${ }^{1}$
}

\section{RESUMO}

\begin{abstract}
O objetivo do presente estudo foi avaliar os efeitos da retirada mecânica das células somáticas do leite cru sobre a composição e a proteólise durante o armazenamento refrigerado do leite pasteurizado. O delineamento experimental utilizado foi o de blocos generalizados ao acaso, no qual foram considerados como blocos as repetições $(n=3)$ e o nível de gordura do leite (desnatado e integral). Utilizou-se um arranjo fatorial de tratamento do tipo $2 \times 2$, constituído por: dois níveis de contagem de células somáticas - CCS (baixa e alta CCS) e pela aplicação ou não da microfiltração ao leite. Foram realizadas, ainda, medidas repetidas no tempo, as quais corresponderam aos dias de coleta do leite pasteurizado durante o período de armazenamento (1, 7, 14 e 21 dias). Os lotes de leite cru de alta (1.000.000cél. $\mathrm{mL}^{-1}$ ) e baixa (100.000cél. $\mathrm{mL}^{-1}$ ) CCS foram submetidos ao desnate centrífugo, à microfiltração em sistema a vácuo e, em seguida, os lotes de todos os tratamentos foram pasteurizados e armazenados por 21 dias sob refrigeração a $6^{\circ} \mathrm{C}$. Não foi identificado efeito da microfiltração sobre a proteólise do leite, indicando que este tratamento não reduziu a taxa de proteólise do leite de alta CCS durante o período de armazenamento. Foi observado efeito significativo do tempo de armazenamento sobre a proteólise, indicando a manutenção de atividade proteolítica mesmo após a pasteurização do leite. Pode-se concluir que o leite com alta contagem de células somáticas apresenta maior taxa de proteólise durante o período de armazenamento que o leite de baixa contagem de células somáticas. A microfiltração como processo de retirada mecânica das células somáticas do leite não reduz a proteólise do leite durante o armazenamento.

Palavras-chave: células somáticas, leite, atividade enzimática, proteólise, lipólise, microfiltração.
\end{abstract}

\section{ABSTRACT}

This study was aimed at evaluating the effects of raw milk somatic cell removal by microfiltration on the composition and proteolysis during refrigerated storage of pasturized milk. A completely randomized block design was used, in which repetitions $(n=3)$ and milk fat level (skimmed and whole milks) were considered as blocks. A 2 X 2 factorial arrangement of treatments was used: milks with two different levels of somatic cell counts - low somatic cell count (LSCC) and high somatic cell count (HSCC) - and, microfiltration or not of milk. Repeated measures during storage time were taken from pasteurized milk at days 1, 7, 14 and 21. LSCC raw milk - 100,000cells $\mathrm{mL}^{-1}$ - and HSCC raw milk - 1,000,000cells $\mathrm{mL}^{-1}$ were obtained from selected cows, skimmed and submitted to vacuum microfiltration. Milk was pasteurized and kept refrigerated at $6^{\circ} \mathrm{C}$ for 21 days. The application of milk microfiltration was efficient on somatic cell removal; however microfiltration had no effect on milk proteolysis which means the treatment did not reduce HSCC milk proteolysis rate during refrigerated storage. Significant effect of storage period on proteolysis was observed indicating that proteolytic activity remained despite milk pasteurization. HSCC milk proteolytic activity was 1,42 times higher than in LSCC milk, during the 21-day of refrigerated storage period. Based on the results of the study, HSCC milk shows a higher proteolytic activity than LSCC milk, during the $6^{\circ} \mathrm{C}$-21 day storage period. Microfiltration, as a somatic cell removal process had no effect on decreasing proteolytic activity of pasteurized milk during the refrigerated storage period.

Key words: somatic cell, milk, enzymatic activity, proteolysis, lipolysis, microfiltration.

\section{INTRODUÇÃO}

O aumento das células somáticas (CS) no leite afeta negativamente a sua composição e o tempo de prateleira dos derivados lácteos, causando enormes prejuízos para produtores e para a indústria de laticínios.

${ }^{1}$ Faculdade de Medicina Veterinária e Zootecnia (FMVZ), Universidade de São Paulo (USP), R. Duque de Caxias Norte, 225, CP 23, 13630-090, Pirassununga, São Paulo, Brasil. E-mail: mveiga@usp.br. Autor para correspondência.

${ }^{2}$ Faculdade de Zootecnia e Engenharia de Alimentos, USP, Pirassununga, SP, Brasil. 
A elevada quantidade de células somáticas do leite resulta em diminuição da vida de prateleira do leite pasteurizado, afetando negativamente a sua qualidade sensorial (SANTOS et al., 2003a; SANTOS et al., 2003b). Isto ocorre pela ação das lipases sobre os triacilglicerídios, resultando no aparecimento de defeitos sensoriais como a rancidez, assim como pela ação de proteases, que causam proteólise da caseína.

As células somáticas do leite, compostas principalmente por neutrófilos e macrófagos, apresentam grande variedade de enzimas proteolíticas e lipolíticas, que são liberadas durante o mecanismo de morte intracelular de microrganismos na mastite subclínica, e podem contribuir de forma significativa para a proteólise e a lipólise dos constituintes do leite (SANTOS et al., 2003a). As concentrações de muitas enzimas ou mesmo a sua atividade enzimática no leite encontram-se aumentadas durante a mastite (AULDIST \& HUBBLE, 1998). Além das enzimas das células somáticas, outras enzimas que têm origem no sangue e que passam através das junções entre as células epiteliais entram em contato com o leite (ANDREWS et al., 1991).

A microfiltração (MF) é um processo de separação por membranas que permite a concentração diferencial dos componentes que são maiores que o diâmetro do poro da membrana (SABOYA \& MAUBOIS, 2000). As principais aplicações da MF na indústria de laticínios são: remoção de bactérias e células somáticas, remoção de gordura do soro e enriquecimento micelar do leite para fabricação de queijos (BRANS et al., 2004). Contudo, a remoção física das células somáticas do leite pela MF não implica necessariamente a reversão dos efeitos negativos que a mastite subclínica acarreta na composição e na qualidade do leite, uma vez que muitas das alterações ocorrem ainda no leite dentro do úbere, antes da ordenha. Desta forma, o objetivo do presente estudo foi avaliar os efeitos da remoção das células somáticas pelo uso da microfiltração do leite sobre a sua composição e sobre a taxa de proteólise durante o armazenamento refrigerado do leite pasteurizado.

\section{MATERIAL E MÉTODOS}

Delineamento experimental

O delineamento experimental utilizado foi o de blocos generalizados ao acaso, no qual foram considerados como blocos as repetições $(n=3)$ e o nível de gordura do leite (desnatado e integral). Utilizou-se um arranjo fatorial de tratamentos do tipo $2 \times 2$, constituído por: dois níveis de células somáticas (baixa e alta CCS) e pela aplicação ou não da microfiltração do leite, adicionado do fator medidas repetidas no tempo, as quais corresponderam às avaliações do leite pasteurizado durante o período de armazenamento (1, 7, 14 e 21 dias).

Seleção de vacas e coleta de leite

Para a seleção das vacas, coletaram-se previamente amostras individuais de leite após a ordenha de todas as vacas em lactação do rebanho leiteiro da Universidade de São Paulo (USP), Pirassununga-SP, as quais foram submetidas para análise de CCS e composição (gordura, proteína bruta, lactose, sólidos totais). A análise da CCS foi realizada por citometria fluxométrica, utilizando-se o equipamento Bentley Somacount 500 (Bentley Instruments Inc. Chasca, MN, USA), e as análises de composição foram baseadas em metodologia por absorção infravermelha no equipamento Bentley 2000 (Bentley Instruments Inc. Chasca, MN, USA). Todas as vacas eram ordenhadas em regime de duas ordenhas diárias.

Foram selecionadas em média quatro vacas cujo leite apresentava baixa CCS (aproximadamente 100.000cél. $\mathrm{mL}^{-1}$ ) e quatro vacas cujo leite apresentava alta CCS (aproximadamente 1.000.000cél. $\mathrm{mL}^{-1}$ ), de forma a manter similares os níveis de gordura e proteína entre si. No dia de cada coleta de leite, as vacas selecionadas foram ordenhadas individualmente na ordenha da manhã, sendo todo o leite coletado separadamente e a sua produção medida. O leite cru de cada vaca selecionada foi armazenado em latões de polipropileno previamente higienizados e imediatamente resfriados a $4^{\circ} \mathrm{C}$.

Processamento e remoção das células somáticas do leite Após o resfriamento, os lotes de leite cru de alta e baixa CCS (10L para cada lote) foram aquecidos a $50^{\circ} \mathrm{C}$ e submetidos ao desnate centrífugo utilizando-se uma desnatadeira. Após o desnate, foram formados os seguintes lotes: leite integral com baixa CCS (tratamento A), leite desnatado de baixa CCS (tratamento B), creme do leite de baixa CCS, leite integral com alta CCS (tratamento E), leite desnatado de alta CCS (tratamento F) e creme do leite de alta CCS.

Os lotes de leite desnatado (tratamentos B e F) foram submetidos à microfiltração em sistema a vácuo. A metodologia para remoção das células somáticas do leite baseou-se nos procedimentos descritos por VERDI \& BARBANO (1988), nos quais a amostra de leite é filtrada em membrana de éster de celulose com diâmetro de poro de 5,0 $\mu \mathrm{m}$ (Millipore, Brasil), em sistema a vácuo. O sistema era composto por uma bomba laboratorial de vácuo (marca Quimis, Brasil) e um suporte de vidro para filtração com diâmetro de 47mm (Phenomenex, USA). Para maior eficiência da 
microfiltração, o leite foi previamente aquecido em banho-maria a $50^{\circ} \mathrm{C}$.

Após a microfiltração, foram obtidos os seguintes lotes: leite desnatado microfiltrado com baixa CCS (tratamento C) e leite desnatado microfiltrado com alta CCS (tratamento G). Os leites integrais, desnatados e os cremes de alta e baixa CCS foram submetidos à análise de gordura do leite pelo método de Gerber (PEREIRA et al., 2001), para a padronização dos lotes de leite integral microfiltrado com baixa (tratamento D) e alta CCS (tratamento $\mathrm{H}$ ).

Os lotes de leite de todos os tratamentos foram transferidos para erlenmeyers de vidro de $500 \mathrm{~mL}$ previamente higienizados e submetidos à pasteurização lenta $\left(65^{\circ} \mathrm{C}, 30\right.$ minutos) em banho-maria. Imediatamente após a pasteurização, foram coletadas amostras de leite de todos os tratamentos para confirmar a eficácia da pasteurização pelas provas enzimáticas da fosfatase e de peroxidase (PEREIRA et al., 2001). Os lotes de leite de todos os tratamentos foram resfriados à temperatura de $6^{\circ} \mathrm{C}$, embalados individualmente em frascos plásticos (capacidade $50 \mathrm{~mL}$ ) e armazenados por 21 dias sob refrigeração $\left(6^{\circ} \mathrm{C}\right)$ em estufa (modelo te 390 , marca Tecnal, Brasil).

Após o término da pasteurização e do resfriamento do leite, foi adicionado em todos os tratamentos o conservante dicromato de potássio, na concentração final no leite de $0,1 \mathrm{mg} \mathrm{kg}^{-1}$. Tal procedimento foi realizado para evitar a multiplicação microbiana no leite no decorrer do armazenamento, durante 21 dias, e, desta forma, evitar a lipólise e a proteólise de origem microbiana.

\section{Análises do leite cru e após o processamento}

Antes do processamento, foram coletadas amostras de leite cru de todos os tratamentos para realização das análises de composição (proteína bruta, proteína verdadeira, caseína e nitrogênio não-protéico, gordura, lactose e sólidos totais) e a CCS.

Após o processamento (microfiltração e pasteurização), foram coletadas amostras de leite dos diferentes tratamentos no primeiro dia (imediatamente

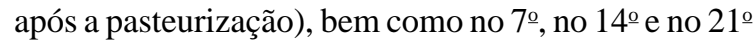
dia com vistas à execução das análises laboratoriais. Para as amostras coletadas no primeiro dia, foram realizadas as seguintes análises: determinação da concentração de ácidos graxos livres no leite (expressa em meq $\mathrm{kg}^{-1}$ ), concentração de nitrogênio total (NT), concentração de nitrogênio não-protéico (NNP) e concentração de nitrogênio não-caseinoso (NNC). Para as amostras coletadas no 7ํㅡㄹ no $14^{\circ}$ e no $21^{\circ}$ dia, foram realizadas as análises de ácidos graxos livres no leite (expressas em meq $\mathrm{kg}^{-1}$ ) e da concentração de nitrogênio não-caseinoso (NNC). Todos os resultados da concentração de nitrogênio foram expressos como equivalentes de proteína, utilizando-se o fator de conversão 6,38. A redução da relação caseína/proteína verdadeira (PV) a partir do dia da pasteurização e durante a armazenagem foi utilizada como medida da proteólise do leite. Imediatamente após a pasteurização e no $21^{\text {o }}$ dia de armazenamento, foram coletadas amostras de leite de todos os tratamentos para realização de análises microbiológicas (contagem bacteriana total, contagem de coliformes totais e fecais), de acordo com metodologia descrita por MARSHAL (1992).

\section{Análise estatística}

Os resultados obtidos foram submetidos à análise de variância, aos quais foram atribuídos como causas principais de variação os efeitos de repetição, CCS, microfiltração (MF), níveis de gordura e a interação dupla (CCS*MF), adicionados do fator medidas repetidas (comando Repeated do Procedimento General Linear Model do SAS ${ }^{\circledR}$, Versão 8.02; SAS Institute Inc., Cary NC) referentes aos quatro diferentes tempos de armazenamento. De acordo com os resultados estatísticos obtidos, foi possível obter as equações de regressão geradas pelo procedimento de regressão múltipla (PROC REG), sendo que as variáveis dependentes foram a lipólise e a proteólise do leite e as independentes foram representadas pelas causas de variação principais.

Metodologias para análises de proteína do leite A determinação da concentração de proteína do leite baseou-se na mensuração do nitrogênio total (NT) pelo método de Kjeldahl, conforme metodologia descrita pela ASSOCIATION OF OFFICIAL ANALYTICAL CHEMISTS (1995); método número 33.2.11; 991.20. O nitrogênio é então multiplicado por um fator $(6,38)$, para que os resultados sejam expressos em proteína total (BARBANO \& CLARK, 1990). As frações de NNC e de caseína do leite foram determinadas através de metodologia descrita por LYNCH \& BARBANO (1998). Através da subtração da concentração de NT e de NNC, foi determinada a concentração de caseína do leite. A concentração de proteína verdadeira do leite foi determinada pela diferença entre a concentração de proteína total e a concentração de NNP, conforme metodologia descrita pela ASSOCIATION OF OFFICIAL ANALYTICAL CHEMISTS (1995); método número 33.2.12; 991.21. Após a determinação da concentração de NNP, fez-se a subtração deste resultado pelo da concentração de NT e, desta forma, pôde-se determinar a concentração de proteína verdadeira. 


\section{RESULTADOS E DISCUSSÃO}

Composição do leite cru

As médias da composição do leite cru (contagem de células somáticas, porcentagem de gordura, proteína bruta, lactose e teor de sólidos totais) estão apresentadas na tabela 1. Os resultados de CCS do leite cru dos diferentes tratamentos confirmaram a eficiência da microfiltração (MF) quanto à remoção das células somáticas do leite $(\mathrm{P}<0,05)$. A média aritmética da CCS do leite integral de baixa CCS foi de 75.000cél. $\mathrm{mL}^{-1}$, enquanto que o leite de alta CCS apresentou média de 1.150.000cél. $\mathrm{mL}^{-1}$. O desnate do leite teve efeito significativo sobre a CCS $(P<0,05)$, sendo que, para os tratamentos de baixa (tratamento A) e alta (tratamento E) CCS, houve redução em 34,6\% (75.000 versus 49.000cél. mL ${ }^{-1}$ ) e em 75,6\% (1.150.000 versus 279.500cél. $\mathrm{mL}^{-1}$ ) da CCS, respectivamente, confirmando resultados obtidos por SANTOS et al. (2003a). Adicionalmente, o desnate seguido da MF resultou em redução da CCS dos tratamentos de baixa (tratamento A) e alta (tratamento E) CCS em 92,6\% (75.000 versus 5.500cél. $\mathrm{mL}^{-1}$ ) e $99,5 \%$ (1.150.000 versus 5.000cél. $\mathrm{mL}^{-1}$ ), respectivamente, o que concorda com resultados apresentados por GIFFEL \& HORST (2004).

A CCS do leite determinou efeito significativo $(\mathrm{P}<0,05)$ sobre a concentração de lactose do leite, cujos teores foram de respectivamente 4,04 e $4,51 \%$ para os leites de alta e baixa CCS. Estes resultados estão de acordo com os obtidos por AULDIST et al. (1995). A mastite determina redução contínua na concentração de lactose no leite com CCS acima de 100.000cél. $\mathrm{mL}^{-1}$. KLEI et al. (1998) demonstraram que quando a CCS aumenta de 83.000 cél. $\mathrm{mL}^{-1}$ para 870.000cél. $\mathrm{mL}^{-1}$, a concentração de lactose é reduzida de $4,97 \%$ para $4,71 \%$. Não foi observado efeito da CCS sobre o teor de sólidos totais do leite.
Composição do leite após o processamento

Todos os tratamentos obtiveram resultados de fosfatase negativa e de peroxidase positiva, indicando pasteurização eficiente. As médias de composição do leite imediatamente após a pasteurização quanto à proteína bruta (PB), ao nitrogênio não-protéico (NNP), à proteína verdadeira $(\mathrm{PV})$, à caseína e à relação entre caseína/PV estão apresentadas na tabela 2. O teor de proteína bruta (PB), proteína verdadeira (PV) e nitrogênio não-protéico (NNP) não sofreram efeito da CCS do leite $(\mathrm{P}>0,05)$. Estes resultados são diferentes daqueles relatados por MA et al. (2000), os quais identificaram que no leite com menor CCS (45.000cél. $\mathrm{mL}^{-1}$ ) a concentração de PB foi menor que aquela observada no leite com maior CCS (849.000cél. $\mathrm{mL}^{-1}$ ): 3,18 versus 3,19\%, respectivamente. De acordo com MA et al. (2000), apesar de o leite com alta CCS apresentar maior porcentagem de $\mathrm{PB}$, a síntese de proteína pelas células epiteliais sofre diminuição, pois foi verificada redução de $30 \%$ na produção diária de leite dos animais com mastite. Por outro lado, os resultados da PB para o leite cru obtidos no presente estudo são similares aos resultados relatados por VERDI et al. (1987), os quais não identificaram diferenças na PB total no leite em função da CCS.

A concentração de caseína apresentou tendência $(\mathrm{P}=0,07)$ de efeito da CCS, sendo que os menores teores foram encontrados no leite com alta CCS em comparação com os dos lotes de leite de baixa CCS. A relação caseína/PV foi reduzida $(\mathrm{P}<0,05)$ nos leites com maiores CCS $(0,82)$, quando comparada com aquela dos leites que apresentavam menores CCS $(0,84)$. Resultados similares foram relatados por KLEI et al. (1998), com uma relação caseína/PV de 0,82 para o leite com baixa CCS (83.000cél. $\mathrm{mL}^{-1}$ ) e de 0,80 para o leite com alta CCS (872.000cél. mL ${ }^{-1}$ ). SANTOS et al. (2003a) relatam que as concentrações de PB no leite cru sofreram efeito significativo da CCS.

Tabela 1 - Médias ( $\mathrm{n}=12$ ) da contagem de células somáticas e da composição química do leite cru distribuídas por nível de gordura, contagem de células somáticas (CCS) e microfiltração.

\begin{tabular}{|c|c|c|c|c|c|c|c|c|c|}
\hline & \multicolumn{2}{|c|}{ Nível de gordura } & \multirow[t]{2}{*}{$\mathrm{P}$} & \multicolumn{2}{|c|}{ CCS } & \multirow[t]{2}{*}{$\mathrm{P}$} & \multicolumn{2}{|c|}{ Microfiltração } & \multirow[t]{2}{*}{$\mathrm{P}$} \\
\hline & Desnatado & Integral & & Alta & Baixa & & Sim & Não & \\
\hline CCS (x1000 cél./mL) & 75,86 & 347,31 & * & 354,93 & 46,77 & * & 14,54 & 384,86 & $*$ \\
\hline Gordura (\%) & 0,46 & 3,34 & * & 2,07 & 1,61 & NS & 1,88 & 1,82 & NS \\
\hline Proteína bruta (\%) & 3,05 & 2,88 & NS & 2,95 & 2,99 & NS & 2,95 & 2,99 & NS \\
\hline Lactose (\%) & 4,39 & 4,13 & * & 4,04 & 4,51 & * & 4,29 & 4,24 & NS \\
\hline Sólidos totais (\%) & 8,80 & 11,23 & * & 9,84 & 10,11 & NS & 10,03 & 9,92 & NS \\
\hline
\end{tabular}

NS: não significativo. $* \mathrm{P}<0,05$ 
Tabela 2 - Médias (n=12) da composição química do leite imediatamente após a pasteurização distribuídas por nível de gordura, contagem de células somáticas (CCS) e microfiltração.

\begin{tabular}{|c|c|c|c|c|c|c|c|c|c|}
\hline & \multicolumn{2}{|c|}{ Nível de gordura } & \multirow[t]{2}{*}{$\mathrm{P}$} & \multicolumn{2}{|c|}{ CCS } & \multirow[t]{2}{*}{$\mathrm{P}$} & \multicolumn{2}{|c|}{ Microfiltração } & \multirow[t]{2}{*}{$\mathrm{P}$} \\
\hline & Desnatado & Integral & & Alta & Baixa & & Sim & Não & \\
\hline Proteína bruta $^{1}(\%)$ & 3,09 & 3,03 & NS & 3,02 & 3,11 & NS & 3,07 & 3,06 & NS \\
\hline Nitrogênio não-protéico¹\%) & 0,23 & 0,23 & NS & 0,24 & 0,22 & NS & 0,23 & 0,23 & NS \\
\hline Proteína verdadeira ${ }^{1}$ (\%) & 2,86 & 2,81 & NS & 2,78 & 2,88 & NS & 2,84 & 2,83 & NS \\
\hline Caseína ${ }^{1}(\%)$ & 2,36 & 2,34 & NS & 2,28 & 2,43 & 0,07 & 2,35 & 2,36 & NS \\
\hline Caseína/ Proteína verdadeira ${ }^{1}$ & 0,83 & 0,83 & NS & 0,82 & 0,84 & * & 0,83 & 0,83 & NS \\
\hline Ácidos graxos livres (meq/kg) & 0,07 & 0,14 & * & 0,12 & 0,09 & NS & 0,11 & 0,10 & NS \\
\hline
\end{tabular}

${ }^{1}$ Resultados baseados em análises executadas pelo método de Kjeldahl. NS: não significativo. *P<0,05.

As concentrações de PV e de caseína encontraram-se numericamente reduzidas nos leites com maiores CCS, quando comparadas com aquelas dos leites que apresentavam menores CCS, ainda que esta diferença não tenha sido estatisticamente significativa. A redução da caseína e da caseína/PV ocorre parcialmente pela degradação da caseína após a sua secreção e por proteases de origem de bactérias, das células somáticas e do sangue (VERDI \& BARBANO, 1988). Pode-se considerar que a principal enzima responsável por esta proteólise é a plasmina, a qual mantém a sua atividade proteolítica mesmo depois da pasteurização (ZACHOS et al., 1992). A plasmina é capaz de hidrolisar $\beta$-caseína transformando-a em pequenos fragmentos de $\gamma$-caseína e em pequenos peptídeos que se difundem para a fração do soro do leite (CRUDDEN et al., 2005). A ação da plasmina pode ocorrer mesmo no leite ainda dentro da glândula mamária ou durante o armazenamento (SAEMAN et al., 1988). Considerando que a carga microbiana do leite cru foi bastante baixa e assim mantida pelo uso de conservante, pode-se assumir que estas alterações na composição do leite foram na sua maior parte associadas com a alta CCS do leite.

Efeito do nível de CCS e da microfiltração sobre a proteólise do leite pasteurizado

A proteólise do leite, no presente estudo, foi avaliada pela redução na relação caseína/PV a partir do momento imediatamente após a pasteurização. Considerou-se que, no primeiro dia após a pasteurização, a relação caseína/PV foi igual a 100\% e que, na medida em que a caseína ia sendo degradada ao longo do período de armazenamento de 21 dias, esta relação sofria redução, conforme pode ser observado na tabela 3 .
A CCS apresentou efeito sobre a redução da caseína/PV no dia $21(\mathrm{P}=0,02)$; todavia, se considerarmos todo o período de armazenamento, foi identificada apenas tendência de efeito da CCS sobre a proteólise $(\mathrm{P}=0,08)$. Não foi identificado efeito da MF sobre a proteólise do leite, indicando que este tratamento não foi eficaz na redução da taxa de proteólise do leite de alta CCS durante o armazenamento refrigerado.

Foi observado efeito significativo do tempo de armazenamento sobre a proteólise, o que significa que a ocorrência de atividade proteolítica foi mantida após a pasteurização do leite. No presente estudo, esta atividade proteolítica aumentada pode ter como origem a ação da plasmina e das proteases dos leucócitos, uma vez que o leite com alta CCS apresenta maiores concentrações de plasmina (LE ROUX et al., 2003), de plasminogênio e de proteases de origem das células somáticas presentes no leite (VERDI et al., 1987). Adicionalmente, a plasmina apresenta resistência térmica ao processo de pasteurização (BASTIAN \& BROWN, 1996) e, mesmo com o tratamento UHT, cerca de $30-40 \%$ da atividade de plasmina no leite persiste (BASTIAN \& BROWN, 1996). Devido ao efeito significativo da interação CCS*Dia $(\mathrm{P}<0,002)$, foi possível determinar as equações de regressão da proteólise para o leite de alta e baixa CCS. As equações relacionando a redução da caseína/PV em função dos dias para os leites de alta (1) e de baixa (2) CCS são: equação 1 (alta CCS): redução caseína/PV = 0,2535 (tempo de armazenamento) - 0,3346 $\left(\mathrm{R}^{2}=0,81\right)$, equação 2 (baixa CCS): redução caseína/PV = 0,1780 (tempo de armazenamento) - 0,1144 ( $\left.\mathrm{R}^{2}=0,55\right)$, onde PV: proteína verdadeira (\%) e tempo de armazenamento é indicado em dias.

Os resultados do presente estudo indicam que o leite pasteurizado e armazenado sob refrigeração 
Tabela 3 - Efeito do nível de gordura, da contagem de células somáticas (CCS), da microfiltração (MF) e do tempo de armazenamento (dia) do leite pasteurizado sobre a proteólise do leite (redução da caseína/PV, \%).

\begin{tabular}{|c|c|c|c|c|c|c|c|}
\hline \multicolumn{3}{|c|}{ Tratamentos } & \multicolumn{4}{|c|}{ Armazenamento (dias) } & \multirow[b]{2}{*}{ Média } \\
\hline Nível de Gordura & CCS & Microfiltração & 1 & 7 & 14 & 21 & \\
\hline \multirow{4}{*}{ Desnatado } & \multirow{2}{*}{ Alta } & Sim & 0 & 0,43 & 2,80 & 3,37 & 1,65 \\
\hline & & Não & 0 & 0,83 & 3,30 & 4,63 & 2,19 \\
\hline & \multirow{2}{*}{ Baixa } & Sim & 0 & 1,23 & 3,03 & 3,83 & 2,03 \\
\hline & & Não & 0 & 1,10 & 2,53 & 3,53 & 1,79 \\
\hline \multirow{4}{*}{ Integral } & \multirow{2}{*}{ Alta } & Sim & 0 & 1,40 & 3,27 & 4,30 & 2,24 \\
\hline & & Não & 0 & 1,03 & 2,07 & 4,00 & 1,78 \\
\hline & \multirow{2}{*}{ Baixa } & Sim & 0 & 0,63 & 1,40 & 2,30 & 1,08 \\
\hline & & Não & 0 & 0,83 & 1,20 & 2,70 & 1,18 \\
\hline \multicolumn{8}{|c|}{ Efeitos Principais } \\
\hline Desnatado & & & 0 & 0,90 & 2,92 & 3,84 & 1,91 \\
\hline \multirow[t]{5}{*}{ Integral } & & & 0 & 0,98 & 1,98 & 3,33 & 1,57 \\
\hline & Alta & & 0 & 0,93 & 2,86 & 4,08 & 1,96 \\
\hline & Baixa & & 0 & 0,95 & 2,04 & 3,09 & 1,52 \\
\hline & & Sim & 0 & 0,93 & 2,63 & 3,45 & 1,75 \\
\hline & & Não & 0 & 0,95 & 2,28 & 3,72 & 1,74 \\
\hline \multicolumn{8}{|c|}{ Dados Médios } \\
\hline Média & & & 0 & 0,94 & 2,45 & 3,58 & 1,74 \\
\hline $\mathrm{DP}$ & & & 0 & 0,8 & 1,7 & 1,7 & 1,84 \\
\hline \multicolumn{8}{|c|}{ Probabilidades estatísticas - Efeitos principais } \\
\hline CCS & & & 0 & NS & NS & 0,02 & 0,08 \\
\hline MF & & & 0 & NS & NS & NS & NS \\
\hline CCS*MF & & & 0 & NS & NS & NS & NS \\
\hline Dia & & & & & & & 0,001 \\
\hline CCS*Dia & & & & & & & 0,002 \\
\hline MF*Dia & & & & & & & 0,02 \\
\hline CCS*MF*Dia & & & & & & & NS \\
\hline
\end{tabular}

NS: não significativo.

sofreu efeito significativo das proteases de origem das células somáticas, uma vez que o leite foi conservado e não apresentou multiplicação microbiana durante a armazenagem. Segundo LE ROUX et al., (1995), a CCS está correlacionada com a proteólise $(\mathrm{r}=0,55)$, enquanto que BASTIAN \& BROWN (1991) descreveram que, em amostras de leite com CCS variando de 100.000 a 300.000cél. $\mathrm{mL}^{-1}$, não foi identificada correlação entre CCS e proteólise, destacando que a proteína do leite pode ser degradada mesmo em amostras com baixa CCS. De acordo com LE ROUX et al. (1995), a plasmina não é a única enzima que degrada a caseína em amostras de leite de origem de animais com mastite subclínica. Desta forma, as proteases de origem das células somáticas e do sangue também apresentam papel importante sobre a proteólise do leite durante o período de armazenamento.
De acordo com as equações (1) e (2), é possível estimar que a taxa de proteólise do leite com alta CCS é 1,42 vezes maior que a do leite com baixa CCS, durante o período de 21 dias de armazenamento a $6^{\circ} \mathrm{C}$. Para o leite com alta CCS após pasteurização, ocorre redução da relação caseína/PV em 0,253 unidades percentuais para cada dia de armazenamento durante 21 dias. O efeito da CCS sobre a proteólise obtido no presente estudo é menor que aquele relatado por SENYK et al. (1985), que estudaram a proteólise do leite pasteurizado conservado e armazenado por 14 dias a $6,7^{\circ} \mathrm{C}$. Os autores determinaram que a proteólise no leite com CCS $>10^{6}$ cél. $\mathrm{mL}^{-1}$ foi cerca de 4 vezes maior que aquela verificada no leite com CCS $<10^{5}$ cél. $\mathrm{mL}^{-1}$.

De acordo com SANTOS et al. (2003a), para o leite armazenado a $6^{\circ} \mathrm{C}$, a relação caseína/PV sofre aumento de 0,017 unidades percentuais para cada 
incremento de $\log$ CCS (x10 cél. $\mathrm{mL}^{-1}$ ) no primeiro dia de armazenamento, enquanto que, aos 21 dias de armazenagem, haveria aumento de 1,12\% na proteólise do leite para cada $\log$ CCS (x10 cél. $\mathrm{mL}^{-1}$ ).

SANTOS et al. (2003b) relataram que o leite torna-se inapropriado para o consumo humano pela presença de alterações sensoriais causadas pela proteólise, quando a redução na relação caseína/PV é superior a 4\%. Considerando-se este limite de proteólise (4\% na redução da caseína/PV), SANTOS et al. (2003a) estimaram que a vida de prateleira do leite pasteurizado, independentemente da multiplicação microbiana, para a temperatura de armazenamento de $6^{\circ} \mathrm{C}$, foi de aproximadamente 47 e 15 dias para os leites de baixa e de alta CCS, respectivamente, estes resultados indicam que o leite pasteurizado de baixa CCS, com conservante para impedir a multiplicação de microrganismos, pode ter vida de prateleira de 47 dias em temperatura de armazenamento de $6^{\circ} \mathrm{C}$.

Análises microbiológicas do leite após o período de armazenamento

Para as amostras de leite imediatamente após a pasteurização, todos os tratamentos apresentaram contagem bacteriana total (CBT) inferiores a $10^{4} \mathrm{UFC}$ $\mathrm{mL}^{-1} \mathrm{e}$ não foram detectados coliformes fecais. Ao final do período de armazenamento de 21 dias, as amostras de leite de todos os tratamentos mantiveram CBT inferior a $10^{4} \mathrm{UFC} \mathrm{mL}^{-1}$ e não foram detectados coliformes fecais. Estes resultados confirmam a eficácia do conservante dicromato de potássio em prevenir a multiplicação microbiana do leite e os seus efeitos sobre a proteólise e a lipólise do leite.

\section{CONCLUSÕES}

Com base nos resultados obtidos no presente estudo, pode-se concluir que o leite com alta contagem de células somáticas apresentou maior taxa de proteólise durante o período de armazenamento que o leite de baixa contagem de células somáticas. A microfiltração como processo de retirada mecânica das células somáticas do leite não apresentou efeito em reduzir a proteólise do leite durante o período de armazenamento.

\section{AGRADECIMENTOS}

Os autores agradecem o auxílio financeiro da Fundação de Amparo à Pesquisa do Estado de São Paulo FAPESP, Proc. 03/08045-1.

\section{REFERÊNCIAS}

AOAC I. Official methods of analysis. Arlington, VA., 1995. 1200p.

ANDREWS, A.T. et al. Indigenous enzymes in milk. In: FOX, P.F. (Ed). Food enzymology. New York, NY: Elsevier Applied Science, 1991. V.1, p.53-129.

AULDIST, M.J. et al. Changes in the compositional of milk from normal and mastitic dairy cows during the lactation cycle. Australian Journal of Experimental Agriculture, v.35, p.427-436, 1995.

AULDIST, M.J.; HUBBLE, I.B. Effects of mastitis on raw milk and dairy products. Australian Journal of Dairy Technology, v.53, p.28-36, 1998.

BARBANO, D.M.; CLARK, J.L. Kjeldahl method for determination of total nitrogen content of milk: collaborative study. Journal AOAC International, v.73, n.6, p.849-859, 1990 .

BASTIAN, E.D.; BROWN, R.J. Plasmin activity and milk coagulation. Journal of Dairy Science, v.74, p.3677, 1991.

BASTIAN, E.D.; BROWN, R.J. Plasmin in milk and dairy products: an update. International Dairy Journal, v.6, n.5, p.435-457, 1996.

BRANS, G. et al. Membrane fractionation of milk: state of the art and challenges. Journal of Membrane Science, v. 243, n.1-2, p.263-272, 2004.

CRUDDEN, A. et al. Factors affecting the hydrolytic action of plasmin in milk. International Dairy Journal, v.15, n.4, p.305-313, 2005.

GIFFEL, M.C.; HORST, H.C.V.D. Comparison between bactofugation and microfiltration regarding efficiency of somatic cell and bacteria removal. Bulletin of the International Dairy Federation, v.389, p.49-53, 2004.

KLEI, L. et al. Effects of milk somatic cell count on Cottage cheese yield and quality. Journal of Dairy Science, v.81, n.5, p.1205-1213, 1998 .

LE ROUX, Y. et al. Proteolysis in samples of quarter milk with varying somatic cell counts. 1. Comparison of some indicators of endogenous proteolysis in milk. Journal of Dairy Science, v.78, p.1289-1297, 1995.

LE ROUX, Y. et al. Polymorphonuclear proteolytic activity and milk composition change. Veterinary Research, v.34, n.5, p.629-645, 2003.

LYNCH, J.M.; BARBANO, D.M. Indirect and direct determination of the casein content of milk by Kjeldahl nitrogen analysis: collaborative study. Journal AOAC International, v.81, p.763-774, 1998.

MA, Y. et al. Effects of somatic cell count on quality and shelflife of pasteurized fluid milk. Journal of Dairy Science, v.83, p.1-11, 2000.

Ciência Rural, v.36, n.5, set-out, 2006. 
MARSHAL, R.T. Standard methods for the examination of dairy products. 16.ed. Washington, DC.: American Public Health Association, 1992. 546p.

PEREIRA, D.B.C. et al. Físico-química do leite e derivados - Métodos analíticos. Juiz de Fora: Epamig, 2001. 234p.

SABOYA, L.V.; MAUBOIS, J. Current developments of microfiltration technology in the dairy industry. Lait, v.80, n.6, p.541-553, 2000.

SAEMAN, A.I. et al. Effect of mastitis on proteolytic activity in bovine milk. Journal of Dairy Science, v.71, n.2, p.50512, 1988.

SANTOS, M.V. et al. Effect of somatic cell count on proteolysis and lipolysis in pasteurized fluid milk during shelf-life storage. Journal of Dairy Science, v.86, p.2491-2503, 2003a.
SANTOS, M.V. et al. Sensory threshold of off-flavors caused by proteolysis and lipolysis in milk. Journal of Dairy Science, v.86, p.1601-1607, 2003b.

SENYK, G.F. et al. Proteolysis in milk associated with increasing somatic cell counts. Journal of Dairy Science, v.68, n.9, p.2189-2194, 1985

VERDI, R.J.; BARBANO, D.M. Preliminary investigation of the properties of somatic cell proteases. Journal of Dairy Science, v.71, n.2, p.534-538, 1988.

VERDI, R.J. et al. Variability in true protein, casein, nonprotein nitrogen, and proteolysis in high and low somatic cell milks. Journal of Dairy Science, v.70, n.2, p.230-242, 1987.

ZACHOS, T. et al. Effects of mastitis on plasminogen activator activity of milk somatic cells. Journal of Dairy Research v.59, p.461-467, 1992. 